\title{
MILKA CASTRO LUCIC (Ed.), LOS PUENTES ENTRE LA ANTROPOLOGÍA Y EL DERECHO. Orientaciones desde la Antropología Jurídica. Santiago, Programa de Antropología Jurídica e Interculturalidad, Facultad de Derecho, Universidad de Chile, 2014, 446 pág.
}

La obra aquí reseñada constituye una excelente y necesaria referencia para el público latinoamericano en general y chileno en particular. El texto se publicó en 2014 y fue resultado de un taller realizado en 2009. Este taller, tal cual se señala en el prólogo, buscó poner en debate miradas interdisciplinarias de lo que se conoce como Antropología Jurídica.

Los trece artículos contenidos en el libro son de alta calidad, resultado nada casual si uno presta atención a sus autores: todos ellos ocupan la primera línea de estos debates en América Latina, comenzando por su editora, la antropóloga Milka Castro, cofundadora de RELAJU, la red de antropología jurídica más importante de la región. Le acompañan otros cofundadores y referentes obligados de la discusión, Diego Iturralde, Esther Sanchez Botero, Morita Carrasco, Jane Collier, Maria Teresa Sierra, Victoria Chenaut, Sarela Paz, Cristóbal Carmona, Antonino Colajanni, Sébastien Grammond, Carlos Marés e Ignasi Terradas.

El libro constituye un aporte en cuanto es, en primer lugar, un texto tremendamente informativo, al señalar con absoluta claridad qué es la antropología jurídica, así como los aportes y limitaciones de esta subdisciplina con pretensiones reales de interdisciplinariedad. Esto de la interdisciplinariedad a propósito del artículo de Carlos Marés, quien apunta a que la antropología jurídica representaría una encrucijada donde el jurista y el antropólogo aportan sus métodos y conocimientos intentando superar la vieja división de tareas en disciplinas especializadas que impuso la ciencia moderna, cuestión que es central en el debate por el conocimiento y su producción, en el sentido de abogar para retomar una perspectiva unificadora de los procesos sociales. Muchos autores, fundamentalmente de corte marxista vieron esta posibilidad en la economía política. Carlos Marés, sin decirlo directamente, nos sugiere que tal vez hoy el campo de la justicia pueda ser el soporte de un nuevo y necesario intento en esta dirección.

En el mismo sentido de informar y precisar qué es eso que llamamos antropología jurídica, el artículo de Diego Iturralde, la combinación perfecta entre abogado y antropólogo, revela con la simpleza y lucidez que lo caracteriza, cuál es ese ámbito. Iturralde, usando otras palabras, nos muestra cómo el mundo del derecho ha transitado hacia una mayor apertura en las consideraciones de otras formas diversas de hacer justicia o relevar derechos. A eso se le llama antropología jurídica, a un conjunto de investigaciones que combinando estrategias metodológicas y analíticas de las ciencias jurídicas y antropológicas, ha puesto sobre el debate la cuestión de acceso y disfrute de derechos específicos de los pueblos, es decir el derecho a un derecho y justicia propia. ¿Y cómo abordar el estudio y análisis de estos debates? Una 
buena alternativa es seguir los pasos expuestos por Jane Collier a partir del método de estudio de caso como herramienta útil para analizar los conflictos. Señala Collier que los casos no son un fin en sí mismos, sino que sirven para suministrar datos que respondan a preguntas de investigación más amplias, como los intentos por descubrir las leyes de un "pueblo", para comparar cómo los jueces razonan, para graficar cambios históricos, para analizar procesos políticos y sistemas de estratificación, para documentar pluralismo jurídico o para mostrar interacciones entre regímenes políticos. A lo que, evidentemente, podríamos agregar, para mostrar también las tensiones, contradicciones y abusos de los sistemas jurídicos.

Es también importante el libro en cuanto muestra las raíces históricas de la antropología jurídica. En línea con esa permanente necesidad de las disciplinas jóvenes de mostrar que tienen historia, todos los autores hacen referencia a la historia del debate, a sus antecedentes, precursores y principales temas. Destacan en particular los artículos de Milka Castro y de Ignasi Terradas, cuyos trabajos deberían ser materia obligada para todo estudiante de antropología y de derecho, sobre todo de antropología, porque muestran cómo en el origen de esta disciplina la preocupación es fundamentalmente política. La antropología sería una antropología política y dentro de ella, jurídica. Y así es. Muchos de los primeros antropólogos, como se sabe, fueron abogados que se preocuparon por conocer las formas de organización social, lo que en definitiva cohesionaba a las denominadas "sociedades primitivas". Como lo señala el artículo de Cristóbal Carmona, la antropología habría nacido subordinada al derecho, en el sentido de ser una herramienta del colonialismo aportando información de los pueblos colonias con el objeto de mejorar las formas de gobierno y control. Y, aunque con matices, se puede estar de acuerdo -los parientes vergonzosos de la antropología- no puede olvidarse que dentro de este contexto geopolítico, la antropología aportó mucho más a la construcción de un mundo descolonizado que a este oscuro pasado.

Efectivamente la antropología nace vinculada al orden imperial. Busca conocer lo que cohesiona a las "sociedades primitivas". Anda en busca de la política, por ello llega al parentesco y lo vuelve un ámbito propio y exclusivo, porque encuentra que allí donde no hay Estado, búsqueda tan frenética de los primeros antropólogos y/o viajeros, es el parentesco, entre otros, lo que regula la estructura social, y se dice estructura social, porque van a ser los británicos quienes primero y más abundantemente van a aportar en este campo. No es casualidad que en muchos de estos artículos se citen numerosos antropólogos de dicha tradición, especialmente a uno de los más importantes y contemporáneos, me refiero a Max Gluckman.

Luego, efectivamente la antropología se encarga de poner orden a este mundo caótico, de reivindicarlo. Es decir allí donde la ciencia política y la filosofía política veían posibilidad de caos al no distinguir un Estado, los primeros antropólogos contemporáneos, de Malinowski y Boas en adelante, vieron orden. Cuando todo el mundo hablaba de la vida salvaje, sin haber visto nunca a ninguno de ellos, la antropología se enfrentó a este salvaje de carne y hueso y oh, sorpresa, encontró que tenían cultura, que tenía instituciones políticas, que tenían sistemas de justicia, es decir terminó mostrando que aquel mundo en tinieblas que describían los viajeros del siglo XIX tenía orden y luz. 
Posteriormente la antropología tomó un cauce que, como bien lo han definido otros autores, en particular Esteban Krotz, otro referente central de la antropología política y jurídica, reflejó las estructuras de la alteridad. Los cambios sociopolíticos del siglo $\mathrm{XX}$ se fueron marcando en la antropología. Su rumbo no fue otro que los cambios que se manifestaban en el escenario social. A los procesos de descolonización, vinieron los cambios de paradigmas en la disciplina. No se entiende por ejemplo la Declaración de Barbados (1971) sin antes comprender el indigenismo y sus límites. De este modo, si bien efectivamente la antropología pudo servir en sus inicios a un proyecto colonizador, su historia ha mostrado cómo también después de purgar esas culpas, se abocó a un trabajo comprometido con la emancipación de las personas con las cuales trabaja. Que hoy exista un ámbito llamado antropología jurídica es el reflejo por excelencia de este compromiso.

Regresando al aporte histórico de los artículos, hay que señalar que a la par de mostrar la historia de la antropología jurídica, se manifiesta una mirada de presente y futuro, particularmente en torno a las tareas pendientes. $Y$ allí cobran enorme relevancia los artículos de María Teresa Sierra, de Esther Sanchez Botero, de Morita Carrasco, de Sarela Paz y de Victoria Chenaut, todas ellas explorando los límites del escenario político jurídico actual y evidenciando la necesidad de trascender dichos límites para incorporar en un marco con mayor amplitud las dinámicas de distintos grupos humanos diferenciados que interpelan las estructuras, en especial al Estado, pero también a las ciencias sociales en general y a la antropología en particular.
Este debate se enriquece notablemente con experiencias de otras latitudes. Los artículos de Antonino Colajanni, que aborda la historia de la antropología jurídica en Italia, y el de Sébastien Grammond, que aborda el caso canadiense y la interesante problemática de la apropiación de la identidad indígena por parte del derecho, sirven como espejos permanentes para seguir la pista de procesos de similar orden que ocurren en nuestra región.

El conjunto de artículos que forman parte de este libro constituye una suma de aportes para el análisis de lo jurídico desde lo antropológico. Para empezar se deja constancia sobre la relevancia del campo jurídico como plataforma que permite posicionar las luchas y reivindicaciones de los pueblos indígenas y sus derechos. Más allá de las enormes limitaciones observadas en la aplicación de la batería de derechos desarrollados en el ámbito internacional, el campo jurídico sigue mostrando ser un espacio potencialmente fértil para la reivindicación de sus derechos. Luego, se impone la necesidad de trascender el monismo jurídico, pues a pesar del hecho irrefutable del pluralismo jurídico, los artículos muestran la necesidad de una vigilancia permanente, puesto que se mantienen enclaves monoculturales, euro y androcéntricos, en la administración y práctica de la justicia. De allí que sea permanente la necesidad de una mirada crítica fuera y dentro de los sistemas jurídicos indígenas. La mirada atenta y vigilante no solo debe estar dirigida hacia la justicia ordinaria, ya que todos los sistemas jurídicos contienen inequidades y procedimientos discriminatorios, incluidas las justicias indígenas. En este sentido es bueno recordar el aporte de Boaventura de Sousa Santos, en términos de mirar constantemente a todas las culturas como incompletas y por 
tanto perfectibles. Es importante entonces estar atentos al ejercicio del derecho propio en un marco sin esencialismos.

Y aquí es importante el aporte que hoy puede ofrecer la antropología, en particular a través del trabajo etnográfico, pues una cosa es la letra del derecho y otra es su aplicación práctica. Muchos casos, el caso del TIPNIS en el oriente boliviano es paradigmático, muestran de manera dramática la distancia que puede existir entre letra e implementación. En una reunión de RELAJU ocurrida hace algunos años en Sucre, uno de los temas centrales fue el debate en torno al derecho a Consulta contenido en la legislación internacional ¿qué hacer con la consulta? parecieron preguntarse los asistentes a dicha reunión, ¿se reivindica o descarta? ¿Se trata de una herramienta poderosa o es mero teatro? La conclusión, más o menos consensuada, fue que el derecho a consulta no puede ser abandonado, sino más bien debe ser fortalecido, por ejemplo volviéndolo realmente vinculante. Asimismo se destacó que además de las consecuencias en las decisiones, La consulta, posee elementos positivos que trascienden lo meramente jurídico, por ejemplo cuando se inicia el proceso en las comunidades indígenas se producen nuevos escenarios en dichos mundos locales, elementos que por lo general derivan en procesos crecientes de empoderamiento. Finalmente, ambos ejes, implementación y transformaciones locales, convergen en la necesidad de conocer en detalle los casos concretos donde tienen lugar estos procesos, diríamos, una casuística del debate jurídico en América Latina. Así mismo, cobra relevancia el tema de la Vernaculización/relocalización del derecho internacional. Llevado a un plano más amplio, la necesidad de un estudio de casos deriva en la necesidad de conocer en el plano concreto las formas en que se está desarrollando la articulación/oposición entre, por un lado, los distintos sistemas de justicias englobados en el concepto de pluralismo jurídico, y por otro, cómo, efectivamente, se aplican las disposiciones del derecho internacional y las legislaciones nacionales en los mundos locales.

En suma, el libro Los puentes de la Antropología y el Derecho. Orientaciones desde la Antropología Jurídica, constituye un aporte al debate regional y sobre todo a la discusión de estos temas en Chile, país donde persiste una mirada que niega lo diverso, que tiene dificultades de mirar la alteridad y, peor aún, de ver allí sistemas válidos. De ahí que sea tan importante la aproximación etnográfica, es decir aquella mirada que pretende una comprensión de los procesos a partir de la propia mirada de las personas con la cuales se trabaja; una aproximación que releve el sentido que tienen los procesos sociales, en este caso los jurídicos, para esas personas. Pero no tan solo que releve dichos sentidos, sino que también los sitúe analíticamente, críticamente diríamos, en el horizonte de la interculturalidad, esto es, que dichos sistemas responden a arbitrios culturales y, por tanto, no responden a ninguna naturaleza humana ni principio esencial del universo, sino que son construcciones contingentes. $Y$ esto es fundamental porque nos pone delante de dos escenarios. El primero es la búsqueda de equilibrios de los sistemas jurídicos "otros", el fin perseguido por el pluralismo jurídico, que busca ponerlos en situación de simetría y combatir aquellos que defienden el monismo jurídico y el desprecio por otros sistemas que no respondan a ciertas lógicas dominantes. Pero por otro lado, y con la misma fuerza, esta aproximación crítica a los sistemas jurídicos nos obliga a situarlos a todos, no 
tan solo a los dominantes, en el horizonte de la interculturalidad, es decir aquella idea que nos dice que esto o aquello podría ser de otra manera. Esto nos permite estar atento a una constante: el abuso de una parte de la humanidad por sobre otra. Esta constante tiene múltiples manifestaciones: clase contra clase, etnia contra etnia, pero en el caso de los problemas jurídicos que se analizan en Latinoamérica la constante es el permanente relegamiento y abuso de los derechos de los pueblos indígenas y en particular, interna y externamente, de unos, hombres, contra otras, mujeres.

\section{Claudio Espinoza Araya Director Antropologías del Sur}


